\title{
Locally Advanced Unresectable Sarcoma
}

National Cancer Institute

\section{Source}

National Cancer Institute. Locally Advanced Unresectable Sarcoma. NCI Thesaurus. Code C153477.

A sarcoma that has spread from its orig inal site of growth to nearby tissues or lymph nodes and is not amenable to surgical resection. 